that some or even possibly all "negative" breast cancers may contain receptors in undetectable amounts. This leads to the concept that breast cancers should no longer be regarded as hormone dependent or independent but rather as having varying degrees of dependence. It is particularly interesting that we found that a given tumour may be characterized by its receptor content. Quantitative measurement of this content might assess the degree of hormone dependence of a tumour. We therefore suggest that quantitative rather than qualitative assessment should provide an appropriate criterion in future studies of biochemical and clinical correlations.

We thank the Service d'Anatomie Pathologique, Institut Jules Bordet, for examining the tumours. We also acknowledge the kind help of Dr. J. S. Williams (E.O.R.T.C. Data Center, Institut Jules Bordet) with the statistical analysis of the results, and Professor H. T. Tagnon for discussing the concepts presented.

The sources of the reagents used in the study were as follows: $(2,4,6,7)-{ }^{3} \mathrm{H}$-oestradiol- $17 \beta 100 \mathrm{Ci} / \mathrm{mmol}$ was purchased from the Radiochemical Centre, Amersham, England; charcoal from Merck, Darmstadt, Germany; dextran T-70 from Pharmacia, Uppsala, Sweden; bovine serum albumin fraction $\mathrm{V}$ from the Sigma Chemical Company, St. Louis, Mo., U.S.A.; and M-Partigen plates from Behring-Marburg-Lahn, Germany. All the reagents were analytical grades.

This work was supported by a grant from the Fonds Cancérologique de la Caisse Générale d'Epargne et de Retraite de Belgique and performed within the framework of the Association Euratom, University of Brussels, and University of Pisa.

\section{References}

Braunsberg, H., Killen, E., and Richardson, S. G. (1972). Biochemical fournal, 130, 38p.

Braunsberg, H., et al. (1973). Lancet, 1, 163.

Braunsberg, H., et al. (1973). Lancet, 1, 163.

Bray, G. A. (1960). Analytical Biochemistry, 1, 179.

Erosby, W. H., and Furth, F. W. (1956). Blood, 11, 380.

Engelsman, E., et al. (1973). British Medical fournal, 2,

Feherty, P., Farrer-Brown, G., and Kellie, A. E. (1971). British fournal of Cancer, 25, 697.

Hähnel, R., Twaddle, E., and Vivian, A. B. (1971). Steroids, 18, 681.

Heuson, J. C., et al. (1975). Journal de Gynécologie Obstétrique de la Reproduction. In pres.

Jensen, E. V., et al. (1971). National Cancer Institute Monographs, 34, 55.

Jensen, E. V., et al. (1973). Recent Results in Cancer Research, No. 42, p. 55. London, Heinemann.

Johansson, H., Terenius, L., and Thorén, L. (1970). Cancer Research, 30, 692.

Korsten, C. B., and Persijn, J.-P. (1972). Zeitschrift für klinische Chemie und klinische Biochemie, 10, 502.

Leclercq, G., et al. (1973). European fournal of Cancer, 9, 665.

Leclercq, G., et al. (1973). European fournal of Cancer, $9,665$.

Leung, B. S., et al. (1973 a). Archives of Surgery, 106, ung, B. S.; Manaugh, L. C., and Wood, D. C. (1973 b). Clinica Chimica Acta, 46, 69.

Lowry, O. H.; et al. (1951). Fournal of Biochemical Chemistry, 193, 265.

McGuire, W. L., and DeLaGarza, M. (1973). Fournal of Clinical Endocrinology and Metabolism, 37, 986.

Mancini, G., Carbonara, O. A., and Heremans, J. F. (1965). Immunochemistry, 2, 235.

Sanborn, B. M., Rao, B. R., and Korenman, S. G. (1971). Biochemistry, 10, 4955 .

Savlov, E. D., et al. (1974). Cancer (Philadelphia), 33, 303.

Scatchard, G. (1949). Annals of the New York Academy of Sciences, 51, 660.

Spaeren, U., et al. (1973). European fournal of Cancer, 9, 353.

Trams, G., and Maass, H. (1973). Archiv fitr Gynäkologie, 214, 293.

Trams, G., and Maass, H. (1973). Archiv für Gynä

Wittliff, J. L., et al. (1972). Cancer Research, 32, 1983.

\title{
The HL-A System in Asbestos Workers
}

\section{J. A. MERCHANT, P. T. KLOUDA, C. A. SOUTAR, W. RAYMOND PARKES, SYLVIA D. LAWLER, MARGARET TURNER-WARWICK}

British Medical Fournal, 1975, 1, 189-191

\section{Summary}

In a study of the HL-A system in 56 selected asbestos workers referred to the Pneumoconiosis Medical Panel with definite or suspected asbestosis, the $W 27$ antigen was found more often than among a control population. Six of the 10 asbestos workers with the $W 27$ antigen had definite radiographic evidence of asbestosis compared to 13 out of 46 without the $W 27$ antigen. These observations, if confirmed, suggest that the $W 27$ antigen may provide a useful marker of an enhanced susceptibility to the tissue-damaging effects of asbestos dust.

\section{Introduction}

The incidence and severity of asbestosis-that is, pulmonary fibrosis-are to some extent related to the concentration of dust

Department of Medicine, Cardiothoracic Institute, London SW3 6HP J. A. MERCHANT, M.D., DR.P.H., Brompton Fellow

C. A. SOUTAR, M.B., M.R.C.P., Lecturer

W. RAYMOND PARKES, M.D., M.R.C.P., Honorary Lecturer (Member of Pnemaconiosis Medical Panel)

MARGARET TURNER-WARWICK, D.M., F.R.C.P., Professor of Thoracic Medicine

Department of Cytogenics and Immunology, Royal Marsden Hospital and Institute of Cancer Research, London S.W.3

P. T. KLOUDA, PROM.BIOL., Lecturer

SYLVIA D. LAWLER, M.R.C.P., F.R.C.PATH., Consultant Immunologist and the time since first exposure. This relationship, however, is weaker than in coal pneumoconiosis (Rossiter, 1972). Appreciable differences in the severity of lung disease occur in individuals with apparently similar exposure to asbestos dust, which raises the possibility that unrecognized host factors may alter the individual response to asbestos dust inhalation. That one or more of these host factors may depend on immunological responses in the lung has been suggested by the finding of an increased frequency of antinuclear antibody (A.N.A.) and rheumatoid factor in patients with asbestosis (Pernis et al., 1965; Turner-Warwick and Parkes, 1970) and coal pneumoconiosis (Lippman etal., 1973; Soutar et al., 1974).

Some immune-response genes are believed to be closely linked to the HL-A system-the major histocompatibility system in man-and HL-A antigens have been found to be associated with some diseases having immunological abnormalities (Caffrey and James, 1973; Brewerton et al., $1973 \mathrm{a}, \mathrm{b}, \mathrm{c}$; Schlosstein et al., 1973).

A pilot study of the HL-A system in asbestos workers was therefore undertaken to search for evidence of inherited differences in susceptibility to asbestosis.

\section{Patients and Methods}

The 56 asbestos workers were selected from a study undertaken with the Pneumoconiosis Medical Panel, to which they had been referred because of suspected asbestosis. All had been occupationally exposed to asbestos, mainly as laggers in the insulation industry or in dockyards. Clinical data were recorded on a standard questionnaire, posteroanterior and lateral chest radiographs were taken, and venous blood samples were obtained. All subjects were Caucasian and all but one were men. Their mean age was 57 years (range 37-73), mean duration of exposure to asbestos 22 years $(1-47)$, and mean time since 
first exposure 31 years (12-52). Nineteen (34\%) had A.N.A. or rheumatoid factor or both. The control population consisted of 153 normal Caucasian donors previously typed for HL-A antigens at the Royal Marsden Hospital.

Haematological Studies. - The HL-A antigens were determined by a single-stage microlymphocytotoxicity test modified from KissmeyerNielsen and Kjerbye (1967). We used the antigenic definitions made at the fifth histocompatibility workshop (Dausset and Colombani, 1973) except for the antigen TY, which was described by Gelsthorpe and Doughty (1973). The ABO antigens were typed by standard methods and the sera tested for the presence of cytotoxic antibodies. Serum was used to estimate A.N.A. and rheumatoid factors by standard methods (Soutar et al., 1974).

Interpretation of Radiographs. - The posteroanterior radiograph was read independently by four of us (C.A.S., M.T.W., W.R.P., J.A.M.) using the International Union against Cancer (U.I.C.C.) (1970) classification of the radiographic appearances of pneumoconiosis, the internationally accepted standard for interpreting and grading the type, size, and profusion of pulmonary opacities as well as pleural and other changes associated with pneumoconioses. Radiographs were placed in one of two broad categories of profusion $(\leqslant 1 / 2$ or $\geqslant 2 / 1)$ as determined by at least three of the four readers. At least three readers agreed on the classification in 50 radiographs. The remaining six radiographs were again read independently by three of us (C.A.S., M.T.W., J.A.M.) and the two readings in agreement accepted. By this method, 37 out of the 56 were thought to have little or no evidence of asbestosis (profusion $<1 / 2$ ) while 19 were judged to have moderate to severe asbestosis (profusion $\geqslant 2 / 1$ ). The 37 radiographs judged to show minimal or no asbestosis consisted of 24 in categories $1 / 1$ or $1 / 0$ and 13 in categories $0 / 1$ and $0 / 0$. Ten of the 13 in categories $0 / 1$ and $0 / 0$ had pleural shadows.

\section{Results}

The frequency of the HL-A antigens in asbestos workers and controls is presented in table I. W 27 was three times more common among the asbestos workers than among normal controls, a statistically significant difference $(P<0.01$ with Yates's correction, but not corrected for the number of specificities tested). When W 27 was examined in relation to the radiographic category (table II) there seemed to be an association between W 27 and the severity of asbestosis though this did not reach statistical significance in this small group ( $x^{2}$ test). Six of the 10 patients with W 27 had moderate to severe asbestosis (profusion $\geqslant 2 / 1$ ) compared with 13 out of 46 patients without W 27 .

Those positive for W 27 also tended to have been exposed to asbestos for a shorter period, and their first exposure had been more recent (tables III and IV). There was no apparent association between the W 27 antigen and pleural shadows. None of the 10 subjects with $W 27$ had clinical or radiographic evidence of ankylosing spondylitis. There was a decrease in the frequency of HL-A 9, but not a statistically significant one.

TABLE I-HL-A Antigen Frequencies among 56 Asbestos Workers and 153 Controls. Numbers in Parentheses are Numbers of Patients with each Antigen

\begin{tabular}{|c|c|c|}
\hline HL-A Antigens & $\begin{array}{l}\text { (\%) Frequency in } \\
\text { Asbestos Workers }\end{array}$ & $\begin{array}{l}\text { (\%) Frequency in } \\
\text { Controls }\end{array}$ \\
\hline 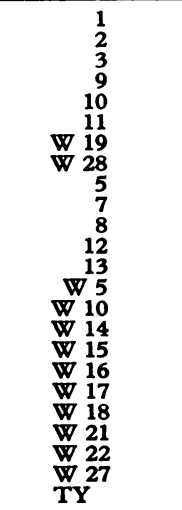 & $\begin{array}{r}33.9(19) \\
55.4(31) \\
19.6(11) \\
5.4(3) \\
10.7(6) \\
12.5(7) \\
21.4(12) \\
12.5(7) \\
12.5(7) \\
21.4(12) \\
33.9(19) \\
21.4(12) \\
1.8(1) \\
7.1 \quad(4) \\
16.1 \quad(9) \\
10.7(6) \\
16.1 \quad(9) \\
7.1 \quad(4) \\
7.1 \quad(4) \\
7.1 \quad(4) \\
3.6(2) \\
0.0(0) \\
17.9(10) \\
1.8(1)\end{array}$ & $\begin{array}{r}39 \cdot 2 \\
45.1 \\
28.1 \\
15.7 \\
11.1 \\
12.4 \\
22.2 \\
6.5 \\
7.2 \\
30.1 \\
27.5 \\
27.5 \\
8.5 \\
11.1 \\
9.8 \\
5.2 \\
8.5 \\
8.9 \\
12.4 \\
10.4 \\
1.6 \\
3.3 \\
5.2 \\
1.2\end{array}$ \\
\hline
\end{tabular}

$x^{2}=6.77 ; P<0.01$.
TABLE II-Presence or Absence of W 27 Antigen and Radiographic Category among 56 Asbestos Workers

\begin{tabular}{c|c|c|c}
\hline $\begin{array}{c}\text { U.I.C.C. } \\
\text { Profusion Category }\end{array}$ & $\begin{array}{c}\text { No. Positive } \\
\text { for W 27 }\end{array}$ & $\begin{array}{c}\text { No. Negative } \\
\text { for W 27 }\end{array}$ & Total \\
\hline \multirow{2}{*}{$2 / 1 / 2$} & 6 & 13 & 19 \\
\hline Total & 4 & 33 & 37 \\
\hline
\end{tabular}

TABLE III-Presence or Absence of W 27 Antigen and Length of Exposure to Asbestos

\begin{tabular}{c|c|c|c}
\hline $\begin{array}{c}\text { Duration of } \\
\text { Exposure (Years) }\end{array}$ & $\begin{array}{c}\text { No. Positive } \\
\text { for W 27 }\end{array}$ & $\begin{array}{c}\text { No. Negative } \\
\text { for W 27 }\end{array}$ & Total \\
\hline $0-14$ & 5 & 12 & 17 \\
$15-26$ & 3 & 16 & 19 \\
$27-47$ & 2 & 18 & 20 \\
\hline Total & 10 & 46 & 56 \\
\hline
\end{tabular}

TABLE IV-Presence or Absence of W 27 Antigen and Time from First Exposure to Asbestos Dust

\begin{tabular}{c|c|c|c}
\hline $\begin{array}{c}\text { Years from } \\
\text { First Exposure }\end{array}$ & $\begin{array}{c}\text { No. Positive } \\
\text { for W 27 }\end{array}$ & $\begin{array}{c}\text { No. Negative } \\
\text { for W 27 }\end{array}$ & Total \\
\hline $\begin{array}{c}0-24 \\
25-34\end{array}$ & 6 & 11 & 17 \\
$35-53$ & 3 & 16 & 19 \\
\hline Total & 1 & 46 & 56 \\
\hline
\end{tabular}

The distribution of A.N.A. and rheumatoid factor did not seem to be associated with the W 27 or any other antigen. Similarly, comparison of other antigens with radiographic category showed no association. Lastly, there was no apparent association of $\mathrm{ABO}$ blood group and radiographic category and no evidence of cytotoxic antibodies.

\section{Discussion}

Some antigens of the HL-A system are associated with disease, the most striking association being that of the $\mathrm{W} 27$ antigen with diseases such as ankylosing spondylitis (Caffery and James, 1973; Brewerton et al., $1973 \mathrm{a}$; Schlosstein et al., 1973), Reiter's syndrome (Brewerton et al., 1973 b), and acute anterior uveitis (Brewerton et al., $1973 \mathrm{c}$ ).

This preliminary study has shown a higher frequency of the W 27 antigen in a small selected group of asbestos workers than in a control population. The data also suggest an association between W 27 and severe asbestosis, an observation that cannot be attributed to longer exposure to asbestos in those with the W 27 antigen.

The results must be regarded as preliminary, but examination of a larger population of asbestos workers, with and without asbestosis, is planned. If confirmed, the association between W 27 and the severity of asbestosis suggests that the antigen may provide at least one marker for identifying individuals with increased susceptibility to the tissue-damaging effects of asbestos dust on the lung.

We thank Mrs. I. Mrazek, Miss S. Singh, and Miss A. Lukoszek for their technical help, Miss H. Rolls for the preparation of the manuscript, and Dr. J. A. G. Carmichael, chief medical adviser (social security), Department of Health and Social Security, for permission to report some of the data used in this study. We gratefully acknowledge grants from the Wellcome Trust, the Tobacco Research Council, and the American Thoracic Society which in part supported workers collaborating in this study.

\section{References}

Brewerton, D. A., et al. (1973 a). Lancet, 1, 904. 
Brewerton, D. A., et al. (1973 b). Lancet, 2, 996
Brewerton, D. A., et al. (1973 c). Lancet, 2, 994.

Caffrey, M. F. P., and James, D. C. O. (1973). Nature, 242, 121

Dausett, J., and Colombani, J. (editors) (1973). Histocompatibility Testing 1972. Copenhagen, Munksgaard.

Gelsthorpe, K., and Doughty, R. W. (1973). Tissue Antigens, 3, 316.

International Union against Cancer (U.I.C.C.) (1970). Chest, 58, 57.

Kissmeyer-Nielsen, F., and Kjerbye, K. E. (1967). In Histocompatibility Testing 1967, ed. E. S. Curtoni, P. L. Mattiuz, R. M. Tosi, p. 381 Copenhagen, Munksgaard.
Lippman, M., et al. (1973). Annals of Internal Medicine, 79, 807.

Pernis, B., Vigliani, E. G., and Selikoff, I. J. (1965). Annals of New York Academy of Science, 132, 112 .

Rossiter, C. E. (1972). Transactions of the Society of Occupational Medicine, $22,83$.

Schlosstein, L., et al. (1973). New England fournal of Medicine, 288, 704.

Soutar, C. A., Turner-Warwick, M., and Parkes, W. R. (1974). British Medical fournal, 3, 145.

Turner-Warwick, M., and Parkes, W. R. (1970). British Medical Fournal, 3,492 .

\title{
Alopecia Areata, Autoimmunity, and Down's Syndrome
}

\author{
ANTHONY DU VIVIER, DOWLING D. MUNRO
}

British Medical fournal, 1975, 1, 191-192

One-thousand control subjects ( 543 male, 457 female) were examined at three of these hospitals. They were suffering from mental retardation caused other than by Down's syndrome. Their average age was 40 years.

The hair of the scalp, beard area, and eyebrows of all the patients was personally examined and a diagnosis of alopecia areata was made on clinical grounds. The covered hair-bearing areas of the body were not examined unless alopecia areata was found on the scalp or face. A sample of blood was taken from the patients with alopecia areata. The haemoglobin total and differential white cell count were estimated and the blood was tested for fluorescent antibodies against nuclei, mitochondria, thyroid epithelium, and colloid and gastric parietal cells. The antithyroglobulin antibody titre, using the tanned red cell agglutination test, and the antimicrosomal antibody titre, using the complement fixation test, were also estimated. were examined for the presence of fluorescent autoantibodies. Antibodies against thyroid components tended to be present in female mongols with alopecia areata in comparison with females in a normal population but not in male mongols. Furthermore, eight out of 23 female mongols $(35 \%)$ with alopecia areata had antibodies against thyroid components compared with two out of 23 female mongols $(9 \%)$ without alopecia areata.

\section{Introduction}

Clinically we have thought that alopecia areata is unusually common in Down's syndrome. Standard works on dermatology (Fitzpatrick et al., 1971; Rook et al., 1972), however, do not mention this association and so we set out to examine the possibility that it exists.

Alopecia areata is thought to be an autoimmune disorder since it is associated with pernicious anaemia, vitiligo, autoimmune adrenal insufficiency, and Hashimoto's thyroiditis (Cunliffe et al., 1969); histologically with lymphocytic infiltrate; and therapeutically the disease responds to steroids. Thus we investigated mongols found to have alopecia areata for antibodies to thyroid epithelium and colloid, DNA, and gastric parietal cells.

\section{Patients and Methods}

We visited eight hospitals for the mentally subnormal near London and examined 1000 patients clinically diagnosed as mongols. We did not record whether their condition was the result of trisomy 21, mosaicism, or translocation because the karyotypes had not been studied in every case. Their ages ranged from 5 to 67 years; 560 were male (average age 30 years) and 440 female (average age 33 years).

Department of Dermatology, St. Bartholomew's Hospital, London EC1A 7BE and Edgware General Hospital, Middx.

\section{Results}

Sixty cases of alopecia areata were found among the 1000 mongols $(6 \%), 23$ in females and 37 in males. In 25 of these cases the condition had progressed to alopecia totalis or universalis. Only one of the 1000 subnormal controls $(0.1 \%)$ had alopecia areata, and no fluorescent antibodies were detected in her serum. Of the 60 mongols with alopecia areata $14(23 \%)$ were positive for fluorescent antibodies. Ten of these were female patients, of whom eight were positive for thyroid antibodies, one was positive for antinuclear factor, and one was positive for gastric parietal cell antibodies. In the four male patients the tests gave only weakly positive results. One had gastric parietal cell antibodies and the other three thyroid antibodies. These numbers in the male patients were no greater than might be expected by chance.

Since eight of the 23 female mongols (35\%) with alopecia areata had thyroid antibodies 23 age-matched female mongols without alopecia areata were investigated. Two patients $(9 \%)$ had antinuclear antibodies and two had thyroid antibodies.

\section{Discussion}

Possibly the prevalence of alopecia areata was a little higher than $6 \%$ since cases confined to the covered hair-bearing areas of the body may have been missed. The high proportion of 25 cases of alopecia totalis and universalis among the 60 alopecia patients is remarkable. Trichotillomania or other hair-loss conditions did not present any problem in the differential diagnosis in these patients.

Muller and Winkelmann (1963) found an increased prevalence of thyroid disease in alopecia areata: of 736 patients with alopecia areata they found that $8 \%$ had thyroid disease, $4 \%$ vitiligo, and $2 \%$ diabetes mellitus. Cunliffe et al. (1968) found thyroid disease associated with vitiligo and showed raised thyroglobulin antibody titres in this condition; moreover, alopecia areata occurred in $18 \%$ of their patients. Cunliffe et al. 